Research

Open Access

\title{
Brain natriuretic peptide levels have diagnostic and prognostic capability for cardio-renal syndrome type 4 in intensive care unit patients
}

\author{
Sunghoon Park', Goo-Yeong Cho², Sung Gyun Kim³ ${ }^{3}$ Yong II Hwang', Hye-Ryun Kang1, \\ Seung Hun Jang ${ }^{1}$, Dong-Gyu Kim¹, Young Rim Song ${ }^{3}$, Young-A Bae ${ }^{4}$ and Ki-Suck Jung ${ }^{1}$
}

\begin{abstract}
1Division of Pulmonary, Allergy and Critical Care Medicine, Department of Internal Medicine, Hallym University Sacred Heart Hospital, 896 Anyang, Kyunggi-do, 431-070, Republic of Korea

2Division of Cardiology, Department of Internal Medicine, Hallym University Sacred Heart Hospital, 896 Anyang, Kyunggi-do, 431-070, Republic of Korea

${ }^{3}$ Division of Nephrology, Department of Internal Medicine, Hallym University Sacred Heart Hospital, 896 Anyang, Kyunggi-do, 431-070, Republic of Korea

${ }^{4}$ Department of Radiology, Hallym University Sacred Heart Hospital, 896 Anyang, Kyunggi-do, 431-070, Republic of Korea
\end{abstract}

Corresponding author: Ki-Suck Jung, pulmoks@hallym.or.kr

Received: 11 Feb 2009 Revisions requested: 17 Mar 2009 Revisions received: 29 Apr 2009 Accepted: 15 May 2009 Published: 15 May 2009

Critical Care 2009, 13:R70 (doi:10.1186/cc7878)

This article is online at: http://ccforum.com/content/13/3/R70

(c) 2009 Park et al.; licensee BioMed Central Ltd.

This is an open access article distributed under the terms of the Creative Commons Attribution License (http://creativecommons.org/licenses/by/2.0), which permits unrestricted use, distribution, and reproduction in any medium, provided the original work is properly cited.

\begin{abstract}
Introduction Limited data are available regarding the diagnostic and prognostic utility of brain natriuretic peptide (BNP) in patients with chronic kidney disease (CKD) in the intensive care unit (ICU) setting.

Methods All patients with CKD and a serum creatinine (Cr) of $2.0 \mathrm{mg} / \mathrm{dl}$ or higher admitted to the ICU between January 2006 and September 2007 were enrolled in this study. The CKD group was divided according to the presence or absence of acute decompensated heart failure (ADHF) into CKD + ADHF and CKD - ADHF groups, respectively. Other patients with ADHF having low $\mathrm{Cr}(<1.2 \mathrm{mg} / \mathrm{dl})$ in the coronary care unit were also recruited as a control group during the same period. BNP levels at the time of admission (admission BNP) were compared amongst these groups. We then sought to determine whether BNP levels could predict the outcome in patients with CKD.
\end{abstract}

Results Of 136 patients with CKD for whom data were available, including 58 on dialysis (42.6\%), 81 (59.6\%) had $\mathrm{ADHF}$ and their estimated glomerular filtration rate (eGFR) was $12.8 \pm 7.3 \mathrm{ml} / \mathrm{min} / 1.73 \mathrm{~m}^{2}$. BNP levels at admission were $2708.6 \pm 1246.9,567.9 \pm 491.7$ and $1418.9 \pm 1126.5 \mathrm{pg} / \mathrm{ml}$ in the CKD + ADHF, CKD - ADHF and control groups $(n=33)$, respectively $(P=0.000)$. The optimal cutoff level in patients with CKD was $1020.5 \mathrm{pg} / \mathrm{ml}$ (area under the curve $=0.944$ ) to detect ADHF from the receiver operating characteristic (ROC) curve. This level was not associated with in-hospital mortality, all-cause death or a composite event (all-cause death and/or new cardiac event). However, a borderline significant association was observed with new cardiac events (hazard ratio $(\mathrm{HR})=4.551 ; P=0.078)$ during the follow-up period $(521.1 \pm$ 44.7 days). Furthermore, continuous variables of BNP and BNP quartiles were significantly associated with new cardiac events in the multivariate Cox model $(\mathrm{HR}=1.001, P=0.041 ; \mathrm{HR}=$ $2.212, P=0.018)$

Conclusions The findings suggest that the level of BNP at the time of admission may be a useful marker for detecting ADHF and predicting cardiac events in patients with CKD in the ICU setting.

ACS: acute coronary syndrome; ADHF: acute decompensated heart failure; ALI: acute lung injury; ARDS: acute respiratory distress syndrome; BNP: brain natriuretic peptide; BUN: blood urea nitrogen; CHF: congestive heart failure; Cl: confidence interval; CKD: chronic kidney disease; Cr: creatinine; CRP: C-reactive protein; CRS: cardio-renal syndrome; EF: ejection fraction; eGFR: estimated glomerulofiltration rate; ICU: intensive care unit; IQR: interquartile range; LAD: left atrial dimension; LV: left ventricle; LVMI: left ventricular mass index; MV: mechanical ventilation; OR: odds ratio; ROC: receiver operating characteristic; SAPS II: simplified acute physiology score II; SOFA: sequential organ failure assessment. 


\section{Introduction}

Cardiovascular disease is a leading cause of death in patients with chronic kidney disease (CKD), for whom the cardiovascular mortality rate is 15 to 30 times higher than in the general population [1,2]. Acute decompensated heart failure (ADHF) occurs in approximately $40 \%$ of patients with CKD and is a strong independent risk factor for mortality $[2,3]$. Recently, the importance of heart-kidney interaction has received widespread attention, and a new classification of the cardio-renal syndrome (CRS) with five subtypes has been proposed. In this classification, CRS type 4 is characterised by a condition of primary CKD contributing to decreased cardiac function, ventricular hypertrophy and/or increased risk of adverse cardiac events $[4,5]$.

Brain natriuretic peptide (BNP), a bioactive cardiac neurohormone secreted from the ventricular myocardium in response to myocardial stretching and volume overload, has diagnostic and prognostic utility in patients with ADHF who do not have CKD [6-9]. BNP levels are also frequently elevated in patients with CKD who have volume overload or concomitant left ventricular dysfunction (i.e., CRS type 4), but the precise mechanisms of these effects are poorly understood [10-12].

In a stable outpatient setting, several studies have shown that the BNP level may be a good predictor for cardiac events and mortality $[13,14]$. However, no previous studies have focused on the significance of BNP in patients with CKD admitted to the intensive care unit (ICU), although such patients in the ICU are expected to have high BNP levels and high cardiovascular event and mortality rates.

Therefore, the present study was performed to investigate whether BNP level at admission may be useful in detecting ADHF and predicting cardiovascular outcome in patients with CKD admitted to the ICU.

\section{Materials and methods Study population}

After obtaining approval of the protocol from the institutional review board, anonymous data from electronic medical records for all adult patients ( $\geq 18$ years old) admitted to the ICU during the 21-month period from January 2006 to September 2007 were reviewed. Informed consent was waived due to the retrospective nature of the study.

For the CKD groups, patients with high serum creatinine $(\mathrm{Cr})$ levels $(\geq 2.0 \mathrm{mg} / \mathrm{dl})$ and with a documented medical history of CKD were included in the study. This CKD group was divided into CKD + ADHF and CKD - ADHF groups according to the presence or absence of ADHF, respectively. Patients who were admitted after cardiopulmonary resuscitation or surgery and those who remained in the ICU for less than 24 hours until death or were discharged against medical advice were excluded from the study. All patients with ADHF having low $\mathrm{Cr}$ levels $(<1.2 \mathrm{mg} / \mathrm{dl})$ and no history of kidney disease who were managed in the coronary care unit during the same period were included as a control group.

\section{Plasma BNP levels}

Our hospital authority has permitted the checking of serum BNP levels in all patients with heart failure since January 2006. Serum BNP levels were measured using the microparticle enzyme immunoassay test (Abbott, Chicago, IL, USA). In this study, all BNP levels were obtained within one hour after presentation at the emergency department or ICU.

\section{Clinical parameters}

The medical records of the patients were reviewed, and the following information was recorded: age, gender, aetiology of CKD, prior history of congestive heart failure (CHF) and coronary artery disease, systolic/diastolic blood pressure, heart rate, admission diagnosis, blood urea nitrogen (BUN), serum $\mathrm{Cr}$, estimated glomerular filtration rate (eGFR) from the abbreviated Modification of Diet in Renal Disease equation, C-reactive protein (CRP), echocardiographic data, sequential organ failure assessment (SOFA) and simplified acute physiology score II (SAPS II).

ADHF was defined as acute dyspnoea (New York Heart Association grade IV) plus overt pulmonary oedema on chest radiographs. To exclude lung diseases such as pneumonia and acute lung injury (ALI)/acute respiratory distress syndrome (ARDS), clinical course (or response to treatment) and final diagnosis at discharge were taken into account. A radiologist reviewed serial chest radiographs of all patients, and two other experts blinded to BNP results independently reviewed all available information and confirmed the final diagnoses. In cases of disagreement, two experts reviewed the cases together and reached a consensus.

ICU stay, ICU mortality, in-hospital mortality, all-cause death, new cardiac events and composite event rate (all-cause death and/or new cardiac event) were analysed. A new cardiac event was defined as the presence of any one of the following: readmission due to heart failure, acute coronary syndrome (ACS) or sudden death.

\section{Data acquisition and analyses}

The association of BNP levels at admission with clinical and laboratory parameters, including biochemistry, left ventricular (LV) dysfunction and severity scores (SOFA and SAPS II), were investigated. Echocardiographic data were restricted to those obtained on the day of ICU admission when the correlations with BNP levels were analysed, but in the multivariate analysis for patient outcomes, all echocardiographic data obtained during the ICU stay were used.

The admission BNP levels were compared among three groups (CKD + ADHF, CKD - ADHF and controls) and the 
optimal cutoff level for differentiating CKD + ADHF from CKD - ADHF patients was chosen. ICU mortality and in-hospital mortality rates were calculated, and the effects of BNP levels at admission on these outcomes were investigated. Other significant factors affecting in-hospital mortality rate were also examined. For evaluation of the prognostic utility of admission BNP on long-term outcomes, the rates of all-cause death, new cardiac events and composite events were investigated. As an independent variable of admission BNP, continuous variables of BNP and BNP quartiles as well as the optimal cutoff level were used. As subgroup analysis, the data restricted to the dialysis-dependent patients were extracted and analysed separately.

\section{Statistical analyses}

Data are expressed as the means \pm standard deviation for continuous variables and as percentages for categorical variables unless otherwise indicated. For comparison of data between two groups, Student's $t$-test was used for continuous data and the chi-squared test was used for categorical data. Comparisons of data among three groups were performed using analysis of variance with Tukey's post hoc test. Correlation analyses were also performed using Pearson's correlations. However, for nonparametric data, the Mann-Whitney U test and Spearman correlation were applied. The ability of admission BNP to predict ADHF was assessed using receiver operating characteristic (ROC) curve analysis. For predicting in-hospital mortality, a multivariate logistic regression analysis was performed and for evaluating the effects of BNP level at admission on long-term outcome, Kaplan-Meier survival curves with log-rank tests and Cox regression analyses based on a multivariate approach were used. Variables with $P<0.10$ on univariate analysis were included in multivariate analysis. $P<$ 0.05 was considered statistically significant. All analyses were conducted using SAS statistical software, EG version (SAS Institute, Inc., Cary, NC, USA).

\section{Results}

\section{Clinical data and admission BNP levels}

The 236 patients with high $\mathrm{Cr}$ levels included 194 patients with CKD, and BNP levels at admission were available for 136 of them. The patients' baseline characteristics are shown in Table 1. Mean age was $66.5 \pm 14.3$ years and $66(48.5 \%)$ patients were male. The aetiology of CKD was diabetes in 80 patients $(58.8 \%)$, and 58 patients $(42.6 \%)$ were dialysis dependent. The most common diagnosis on admission was ADHF (59.6\%), followed by sepsis/infection (8.8\%) and gastrointestinal/liver disease (7.4\%).

The association of BNP levels at admission with clinical and laboratory parameters are shown in Table 2. Systolic and diastolic blood pressure were correlated significantly with BNP levels at admission $(P=0.001$ and $P=0.005$, respectively). Echocardiography was performed in 87 patients (64.0\%) with a median interval of one day (range, 0 to 7 days) after ICU admission. Among these patients, echocardiography was performed on the day of blood sampling for measuring admission BNP only in 45 patients (33.1\%). Admission BNP levels showed significant correlations with LV ejection fraction (EF), LV diameter at end systole and LV mass index (LVMI; $P$ $=0.008, P=0.033$ and $P=0.000$, respectively), and the mean BNP level at admission in patients with LV systolic dysfunction (defined by EF <50\%) was higher than in those without LV systolic dysfunction (2766.4 $\pm 1393.4 \mathrm{pg} / \mathrm{ml}$ vs. $1862.6 \pm 1557.4 \mathrm{pg} / \mathrm{ml}, P=0.032)$. In addition, patients who underwent mechanical ventilator (MV) treatment had higher BNP levels than those without MV treatment (2285.7 \pm $1551.1 \mathrm{pg} / \mathrm{ml}$ vs. $1695.3 \pm 1404.6 \mathrm{pg} / \mathrm{ml}, P=0.041)$.

\section{Diagnostic utility of BNP level at admission}

Eighty-one patients with CKD (59.6\%) were diagnosed as having ADHF. The causes of ADHF were as follows: underdialysis $(n=38)$, ischemia $(n=20)$, infection $(n=13)$, arrhythmia ( $n=5)$, uncontrolled hypertension $(n=4)$ and aortic dissection $(n=1)$. The results of eGFR were not significantly different between 81 patients with CKD + ADHF and 55 with CKD - ADHF $\left(12.2 \pm 6.5 \mathrm{ml} / \mathrm{min} / 1.73 \mathrm{~m}^{2}\right.$ vs. $13.9 \pm 8.2 \mathrm{ml} /$ $\mathrm{min} / 1.73 \mathrm{~m}^{2}$, respectively, $P=0.200$ ). Mean BNP level at admission of 81 patients in the CKD + ADHF group was higher than that in the CKD - ADHF group (2708.6 \pm 1246.9 $\mathrm{pg} / \mathrm{ml}$ vs. $567.9 \pm 491.7 \mathrm{pg} / \mathrm{ml}, P=0.000)$ and was also higher than that in the control group $(1418.9 \pm 1126.5 \mathrm{pg} / \mathrm{ml}$, $P=0.000$; Figure 1a).

The area under the ROC curve for BNP levels at admission to detect ADHF in patients with CKD was 0.944 (95\% confidence interval $(\mathrm{Cl}), 0.907$ to 0.981 ) and the optimal cutoff value was $1020.5 \mathrm{pg} / \mathrm{ml}$ (Figure 2a). The BNP levels at admission representing a negative predictive value of $100 \%$ and a positive predictive value of $100 \%$ were 115.0 and $2382.5 \mathrm{pg} /$ $\mathrm{ml}$, respectively.

\section{BNP levels at admission and in-hospital outcomes}

For the 136 patients with CKD for whom data were available, the median length of ICU stay was three days (range, 1 to 61 days), and ICU mortality and in-hospital mortality rates were $11.8 \%(16 / 136)$ and $16.2 \%(22 / 136)$, respectively. Univariate analysis indicated that BNP level at admission, BNP quartile ranges $(482.8,482.8$ to $1401.0,1401.0$ to 3412.7 and $>3412.7 \mathrm{pg} / \mathrm{ml}$ ) and the optimal cutoff level $(\geq 1020.5 \mathrm{pg} / \mathrm{ml})$ had no effect on ICU stay, ICU mortality rate or in-hospital mortality rate. However, age, sex, BUN, systolic/diastolic blood pressure, albumin, CRP, creatine kinase, LV systolic dysfunction (EF $<50 \%$ ), SAPS II, SOFA and MV treatment were associated with in-hospital mortality $(P<0.10)$. Only MV treatment was an independent predictor of in-hospital mortality on multivariate logistic regression (odds ratio $(\mathrm{OR})=144.896, P=$ 0.042; Table 3). 
Table 1

\begin{tabular}{|c|c|c|}
\hline Variables & CKD group & Control group \\
\hline Age (years) & $66.5 \pm 14.3$ & $74.8 \pm 10.4$ \\
\hline Males/females & $66 / 70$ & $13 / 20$ \\
\hline \multicolumn{3}{|l|}{ Aetiology of CKD } \\
\hline Diabetes & $80(58.8 \%)$ & - \\
\hline Hypertension & $28(20.6 \%)$ & - \\
\hline Chronic glomerulonephritis & $7(5.1 \%)$ & - \\
\hline Others/unknown & $21(15.4 \%)$ & - \\
\hline $\mathrm{BUN}(\mathrm{mg} / \mathrm{dL})$ & $64.8 \pm 34.9$ & $22.2 \pm 4.8$ \\
\hline Serum Cr (mg/dL) & $6.0 \pm 4.1$ & $0.9 \pm 0.2$ \\
\hline eGFR (ml/min/1.73 m²) & $12.8 \pm 7.3$ & $71.4 \pm 15.4$ \\
\hline $\mathrm{BNP}(\mathrm{pg} / \mathrm{mL})$ & $1842.8 \pm 1459.5$ & $1418.9 \pm 1126.5$ \\
\hline Haemodialysis/peritoneal dialysis & $47(34.6 \%) / 11(8.1 \%)$ & \\
\hline \multicolumn{3}{|l|}{ Prior history } \\
\hline Congestive heart failure & $35(25.7 \%)$ & $7(21.2 \%)$ \\
\hline Coronary artery disease & $39(28.7 \%)$ & $9(27.2 \%)$ \\
\hline SAPS ॥ & $41.9 \pm 13.4$ & $29.7 \pm 4.0$ \\
\hline SOFA & $5.8 \pm 2.9$ & $3.3 \pm 3.2$ \\
\hline \multicolumn{3}{|l|}{ Admission diagnosis } \\
\hline ADHF & $81(59.6 \%)$ & $33(100 \%)$ \\
\hline Sepsis/infection & $12(8.8 \%)$ & - \\
\hline Gastrointestinal/liver & $10(7.4 \%)$ & - \\
\hline Neurological disease & $7(5.1 \%)$ & - \\
\hline Others & $26(19.1 \%)$ & - \\
\hline
\end{tabular}

$\mathrm{ADHF}=$ acute decompensated heart failure; $\mathrm{BNP}=$ brain natriuretic peptide; $\mathrm{BUN}=$ blood urea nitrogen; $\mathrm{CKD}=$ chronic kidney disease; $\mathrm{Cr}=$ creatinine; eGFR = estimated glomerular filtration rate; SAPS II = simplified acute physiology score II; SOFA = sequential organ failure assessment.

\section{BNP level at admission and all-cause death, cardiac event and composite event rates}

During the follow-up period for the 136 patients in the CKD group (median, 90 days; range, 1 to 900 days), 40 deaths and 38 new cardiac events (acute heart failure, $n=29 ;$ ACS, $n=$ 7; sudden death, $n=2$ ) occurred. High BNP levels above the optimal cutoff level ( $\geq 1020.5 \mathrm{pg} / \mathrm{ml}$ ) were not associated with composite event-free survival or death-free survival on KaplanMeier curves (log rank, $P=0.234$ and $P=0.989$, respectively; Figures $3 \mathrm{a}$ and $3 \mathrm{~b}$ ), but was significantly related to a higher rate of new cardiac events (log rank, $P=0.003$ ) during the follow-up period (521.1 \pm 44.7 days; Figure $3 c$ ).

Univariate Cox analysis indicated that white blood cells, serum Cr, LVEF, left atrial dimension (LAD), LVMI, CRP, ADHF and high BNP levels $(\geq 1020.5 \mathrm{pg} / \mathrm{ml}$ ) were associated with the occurrence of new cardiac events $(P<0.10$; Table 4$)$. In the multivariate Cox model, serum $\mathrm{Cr}$ and LAD were significantly associated with new cardiac events (hazard ratio $(\mathrm{HR})=$ $0.855, P=0.046 ; \mathrm{HR}=1.083, P=0.034$, respectively) and a high BNP level above the optimal cutoff level ( $\geq 1020.5 \mathrm{pg} /$ $\mathrm{ml}$ ) showed a borderline significant association $(\mathrm{HR}=4.551$, $P=0.078$ ). However, a significant association was observed when continuous variables of BNP level or BNP quartile, instead of optimal cutoff level, were used in the multivariate Cox model $(\mathrm{HR}=1.001, P=0.041 ; \mathrm{HR}=2.212, P=0.018$, respectively).

\section{Dialysis-dependent patients}

Of the 136 patients with CKD, 58 (42.6\%) were dialysis dependent. In this subgroup, admission BNP levels in the CKD + ADHF group $(n=35,60.3 \%)$ were higher than those in the CHF - ADHF group $(3047.2 \pm 1229.3 \mathrm{pg} / \mathrm{ml}$ vs. $632.3 \pm$ $492.2 \mathrm{pg} / \mathrm{ml}, P=0.000$; Figure $1 \mathrm{~b})$. The area under the ROC 
Table 2

\begin{tabular}{|c|c|c|}
\hline Variables & Correlation coefficients & $P$ value \\
\hline Age & -0.146 & 0.090 \\
\hline BUN & -0.063 & 0.464 \\
\hline Serum Cr & 0.013 & 0.884 \\
\hline \multicolumn{3}{|l|}{ Blood pressure } \\
\hline Systolic blood pressure & 0.297 & 0.001 \\
\hline Diastolic blood pressure & 0.238 & 0.005 \\
\hline Heart rate & 0.019 & 0.827 \\
\hline C-reactive protein & -0.074 & 0.407 \\
\hline WBC & -0.056 & 0.529 \\
\hline Haemoglobin & -0.015 & 0.859 \\
\hline Protein & 0.104 & 0.230 \\
\hline Albumin & 0.023 & 0.793 \\
\hline SAPS II & 0.025 & 0.777 \\
\hline SOFA & 0.099 & 0.257 \\
\hline \multicolumn{3}{|l|}{ Cardiac markers } \\
\hline $\mathrm{CK}$ & 0.067 & 0.454 \\
\hline CK-MB & 0.056 & 0.529 \\
\hline Troponin I & 0.066 & 0.460 \\
\hline \multicolumn{3}{|l|}{ Echocardiographic data } \\
\hline LAD & 0.277 & $0.076^{*}$ \\
\hline LV diameter at end systole & 0.347 & $0.033^{*}$ \\
\hline LV diameter at end diastole & 0.283 & $0.066^{*}$ \\
\hline LV mass index & 0.526 & $0.000^{*}$ \\
\hline E/A ratio & -0.125 & $0.495^{\star}$ \\
\hline Deceleration time & 0.198 & $0.303^{*}$ \\
\hline LVEF & -0.391 & $0.008^{*}$ \\
\hline Systolic dysfunction (EF $<50 \%$ vs. $\geq 50 \%$ ) & - & $0.032^{+}$ \\
\hline Diastolic dysfunction (grade $\geq$ II vs. $<$ I) & - & $0.117^{+}$ \\
\hline Mechanical ventilation (yes vs. no) & - & $0.041^{\#}$ \\
\hline
\end{tabular}

*Spearman correlation, ${ }^{+}$Mann-Whitney $U$ test, "student's $t$ test.

$\mathrm{BNP}=$ brain natriuretic peptide; $\mathrm{BUN}=$ blood urea nitrogen; $\mathrm{CK}=$ creatine kinase $\mathrm{CK}-\mathrm{MB}=$ creatinine kinase- $\mathrm{MB} ; \mathrm{Cr}=\mathrm{creatinine} ; \mathrm{E} / \mathrm{A}=\mathrm{ratio}$ of $E$ (peak mitral flow velocity of the early rapid filling) to $A$ (peak velocity of the late filling due to atrial contration); $E F=$ ejection fraction; $L A D=$ left atrial dimension; LV = left ventricle; LVEF = left ventricular ejection fraction; SAPS II = simplified acute physiology score II; SOFA = sequential organ failure assessment; WBC $=$ white blood cell.

curve was 0.957 (95\% Cl, 0.909 to 0.999$)$ and the optimal cutoff level was estimated to be $1064.4 \mathrm{pg} / \mathrm{ml}$ (Figure $2 \mathrm{~b}$ ). High BNP levels ( $\geq 1064.4 \mathrm{pg} / \mathrm{ml}$ ) had no effect on in-hospital mortality, all-cause mortality or composite-event rate during the follow-up period (507 \pm 71 days). The patients with high BNP levels on admission ( $\geq 1064.4 \mathrm{pg} / \mathrm{ml}$ ) had a significantly higher new cardiac event rate than those with low BNP levels on Kaplan-Meier curves (log rank, $P=0.026)$, and the HR was $4.39(P=0.05)$ on univariate Cox analysis.

\section{Discussion}

The results of the present study showed that BNP levels at admission in patients with CKD + ADHF were different from those with CKD - ADHF and low-Cr/ADHF. High BNP was 
Figure 1
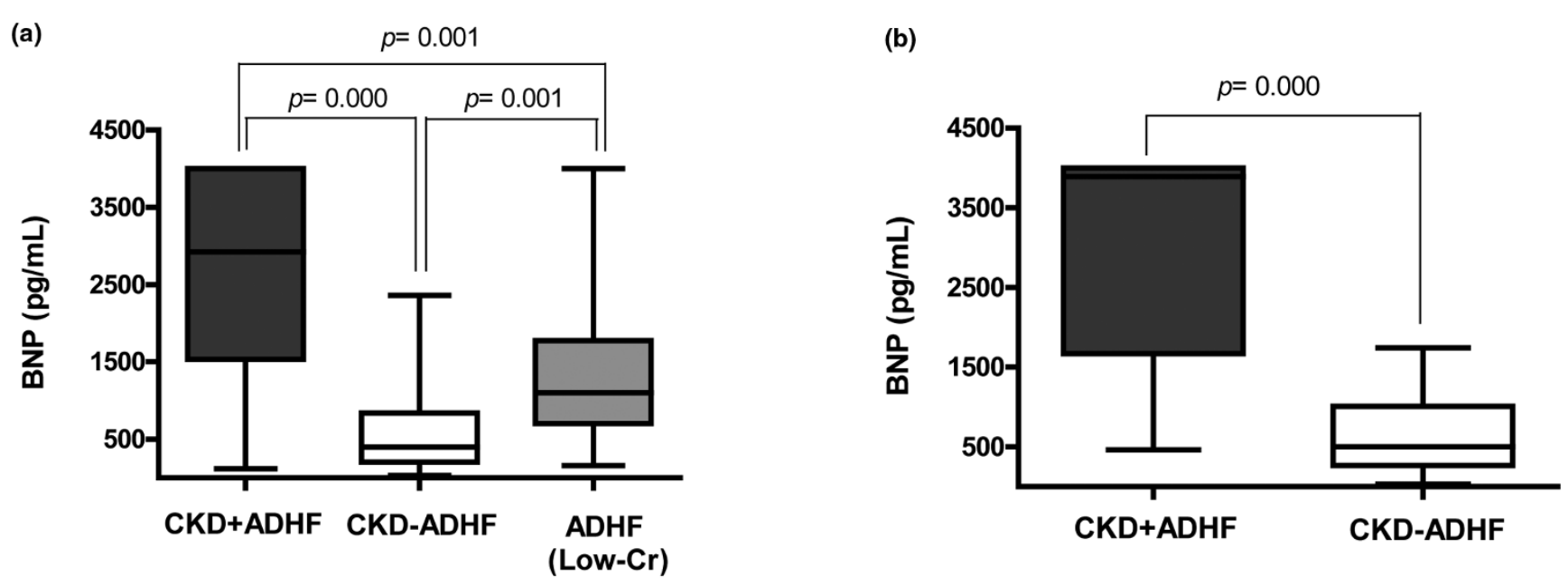

Comparison of BNP levels at admission. (a) Brain natriuretic peptide (BNP) levels at admission among three groups: chronic kidney disease (CKD) + acute decompensated heart failure (ADHF) (mean \pm standard deviation, $2708.6 \pm 1246.9 \mathrm{pg} / \mathrm{ml})$, CKD - ADHF (567.9 $\pm 491.7 \mathrm{pg} / \mathrm{ml})$ and lowcreatinine $(\mathrm{Cr} ;<1.2 \mathrm{mg} / \mathrm{dl}) / \mathrm{ADHF}(1418.9 \pm 1126.5 \mathrm{pg} / \mathrm{ml})$. BNP levels at admission were different among the three groups $(P=0.000$, analysis of variance) and between each pair of groups $(P=0.001, P=0.000$ and $P=0.001$, respectively, Tukey's post hoc test) with the highest mean value in the CKD + ADHF group. (b) BNP levels at admission of 58 dialysis-dependent patients with and without ADHF (3047.2 $\pm 1229.3 \mathrm{pg} / \mathrm{ml} \mathrm{vs}$. $632.3 \pm 492.2 \mathrm{pg} / \mathrm{ml}$, respectively, $P=0.000$ ).

associated with LV systolic dysfunction and was helpful in differentiating patients who had ADHF from those without ADHF among those with CKD in the ICU setting. Although admission BNP was not associated with in-hospital mortality rate, it was an independent predictor of new cardiac events during the fol- low-up period in patients with CKD admitted to the ICU. According to the recent classification of CRS [4,5], the present study indicates that BNP levels have the diagnostic and prognostic capability for CRS type 4 in ICU patients.

Figure 2

(a)

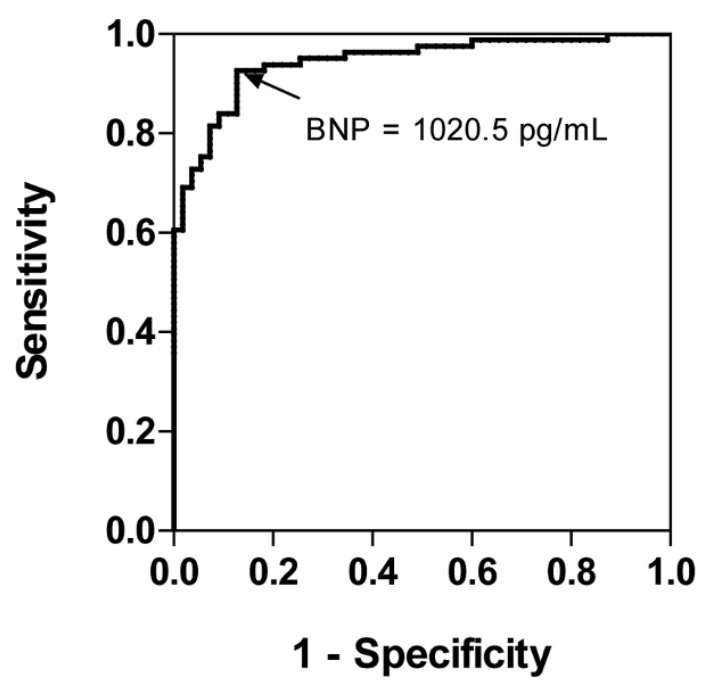

(b)

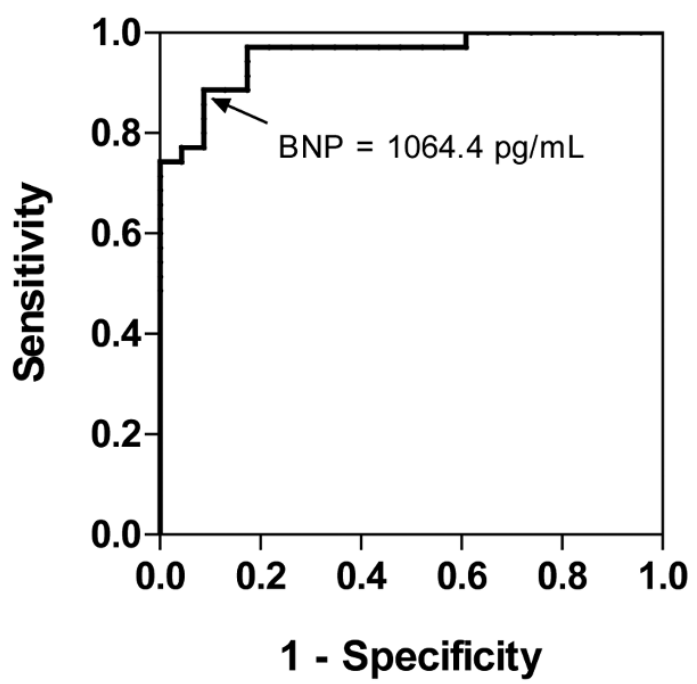

Receiver operating characteristic curves for BNP levels at admission for detecting ADHF. (a) Receiver operating characteristic (ROC) curve for 136 patients with chronic kidney disease (CKD). The area under the curve (AUC) is 0.944 (95\% confidence interval (Cl), 0.907 to 0.981$)$. The optimal cutoff level was estimated to be $1020.5 \mathrm{pg} / \mathrm{ml}$. (b) ROC curve for 58 dialysis-dependent patients. The AUC value was $0.957(95 \% \mathrm{Cl}, 0.909$ to 0.999 ) and the optimal cutoff level was estimated to be $1064.4 \mathrm{pg} / \mathrm{ml}$. BNP = brain natriuretic peptide. 
Univariate and multivariate analyses for predictors of in-hospital mortality

\begin{tabular}{|c|c|c|c|c|}
\hline \multirow[b]{2}{*}{ Variables } & \multicolumn{2}{|c|}{ Univariate anaysis } & \multicolumn{2}{|c|}{ Multivariate analysis } \\
\hline & $P$ value & $P$ value & Odds ratios & $95 \%$ confidence intervals \\
\hline Age & 0.007 & 0.137 & 1.145 & 0.958 to 1.368 \\
\hline Sex & 0.049 & 0.402 & 0.387 & 0.042 to 3.573 \\
\hline BUN & 0.025 & 0.545 & 1.011 & 0.977 to 1.045 \\
\hline Systolic blood pressure & 0.022 & 0.603 & 0.990 & 0.951 to 1.029 \\
\hline Diastolic blood pressure & 0.019 & 0.227 & 0.966 & 0.912 to 1.022 \\
\hline Albumin & 0.007 & 0.967 & 0.960 & 0.067 to 13.701 \\
\hline C-reactive protein & 0.000 & 0.797 & 0.998 & 0.983 to 1.013 \\
\hline CK & 0.078 & 0.061 & 1.003 & 1.000 to 1.006 \\
\hline Systolic dysfunction ( $E F<50 \%)$ & 0.085 & 0.208 & 5.125 & 0.402 to 65.388 \\
\hline SAPS II & 0.000 & 0.556 & 0.936 & 0.749 to 1.168 \\
\hline SOFA & 0.000 & 0.388 & 0.755 & 0.399 to 1.429 \\
\hline MV treatment & 0.000 & 0.042 & 144.896 & 1.195 to 17573.2 \\
\hline
\end{tabular}

$\mathrm{BUN}=$ blood urea nitrogen; $\mathrm{CK}=$ creatine kinase; $\mathrm{EF}=$ ejection fraction; SAPS $\|$ = simplified acute physiology score $\mathrm{II}$; SOFA = sequential organ failure assessment; $\mathrm{MV}=$ mechanical ventilation.

Although the value of BNP has been previously investigated in patients with CKD, most studies were conducted using stable outpatients and little information is available regarding patients with CKD in the ICU setting [13,15-19]. Considering the frequent elevation of BNP levels in the ICU setting due to critical illnesses, for example, sepsis [20,21], acute exacerbation of chronic respiratory failure [22] and ALI/ARDS [23,24], it seems to be more difficult to interpret the measured BNP levels in patients with CKD. However, because this patient group is still at high risk of volume overload (pulmonary oedema) and cardiovascular mortality $[25,26]$, investigation of the BNP value may also be important in patients with CKD in the ICU setting.

Among the clinical and laboratory parameters examined in this study, high systolic/diastolic blood pressure and LV systolic dysfunction (EF $<50 \%$ ) were significantly associated with high BNP levels at admission. However, in contrast to previous studies, age, diabetes and eGFR were not associated with BNP levels at admission [15,16,18]. These discrepancies may have been due not only to the high proportion of patients with ADHF (59.6\%) and dialysis-dependent patients (42.6\%) but also to various critical illnesses causing increases in BNP levels in our study population.

Recently, a few studies of BNP levels among ICU patients with pulmonary oedema have been reported. In a study of 81 ICU patients, Karmpaliotis and colleagues reported a median BNP level in patients with cardiogenic pulmonary oedema of 1260 $\mathrm{pg} / \mathrm{ml}$ (interquartile range (IQR), 540 to $2020 \mathrm{pg} / \mathrm{ml}$ ) vs. 325 $\mathrm{pg} / \mathrm{ml}$ (IQR, 82 to $767 \mathrm{pg} / \mathrm{ml}$ ) in those with ALI/ARDS, and Levitt and colleagues reported mean values in these groups of $747 \pm 476 \mathrm{pg} / \mathrm{ml}$ and $496 \pm 439 \mathrm{pg} / \mathrm{ml}$, respectively, in a study of 54 critically ill patients $[23,24]$. The BNP levels in our series were higher than in these previous studies, both in patients with pulmonary oedema (ADHF) and without. However, in the control group (with ADHF and low $\mathrm{Cr}$ ), the mean BNP level was similar to that in patients with pulmonary oedema reported by Karmpaliotis and colleagues. Considering the similar eGFR levels between CKD + ADHF and CKD ADHF groups, we cannot suggest that the higher BNP levels in the CKD + ADHF group may have been caused by renal dysfunction rather than by pulmonary oedema (i.e., fluid overload causing cardiac stress). However, these observations indicated that both cardiac and renal dysfunction were crucial factors affecting BNP levels, and a significant difference in BNP level was observed between patients with CKD + ADHF and CKD - ADHF despite the frequent high levels of BNP in patients with CKD in the ICU setting.

The optimal cutoff BNP level for differentiating between patients with CKD + ADHF and those with CKD - ADHF was estimated to be $1020.5 \mathrm{pg} / \mathrm{ml}$. However, several arguments can be made against the diagnostic utility of BNP levels in patients with CKD in the ICU due to the many confounding factors beyond renal and cardiac dysfunction in the ICU setting and because the diagnosis of ADHF can be made without BNP levels. Based on the findings of this study, patients with high BNP levels are likely to have LV systolic dysfunction, and the BNP level at admission may be a useful tool for detecting 
Figure 3

(a)

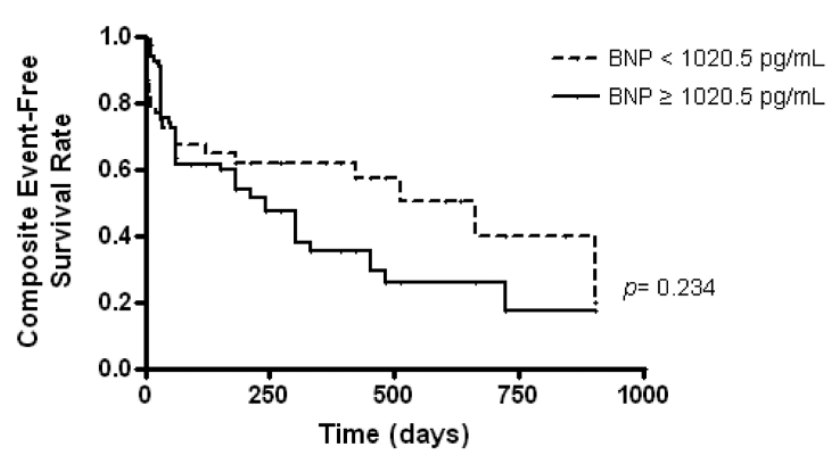

(b)

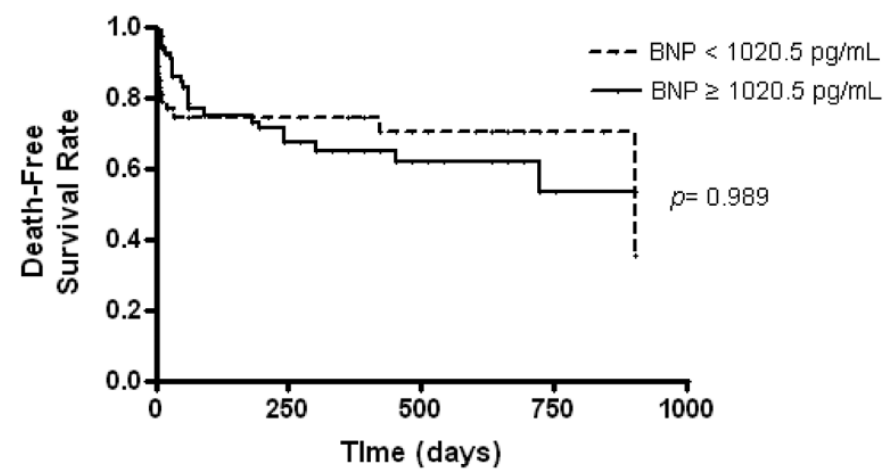

(c)

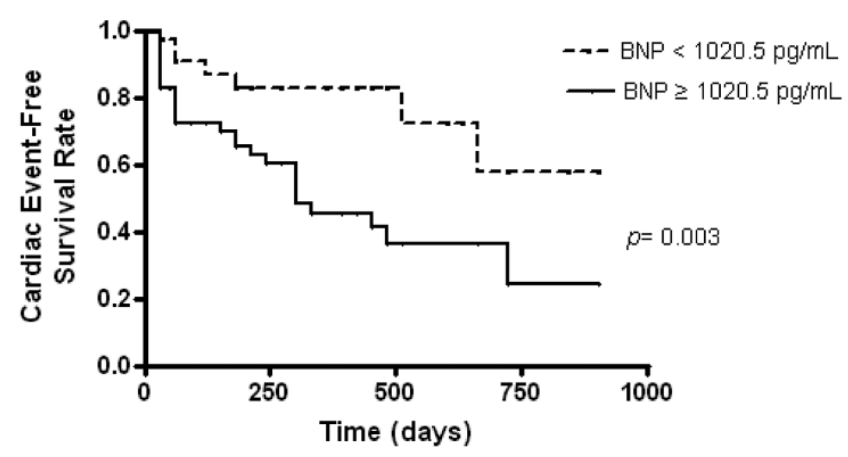

Kaplan-Meier curves for prognosis according to the optimal cutoff level of BNP levels at admission. (a, b) No significant differences in composite event rate or all-cause death were observed between the two groups. (c) Patients with high brain natriuretic peptide (BNP) levels $(\geq 1020.5 \mathrm{pg} / \mathrm{ml})$ had significantly higher cardiac event rates during the follow-up period than those with low BNP levels $(P=0.003)$.

ADHF in patients with CKD in the ICU setting. This possibility should be investigated in a future large-scale prospective study.

In terms of hospital outcome, admission BNP was not associated with ICU stay, ICU mortality rate or in-hospital mortality rate in this study, and MV treatment was the only significant factor predicting in-hospital mortality in 136 patients with CKD for whom BNP level data were available. Unfortunately, very little information is available on hospital outcomes in patients with CKD admitted to the ICU to which we can either reference or compare our results (in-hospital mortality rate, 16.2\%). Based on this study, hospital outcomes were not dependent on BNP level at admission, but rather some other factor(s).

With regard to the prognostic role of BNP level, several studies support the utility of BNP in the long-term prognosis of patients with CKD; these studies consistently demonstrated a positive relation of BNP levels to long-term outcomes, such as all-cause death and cardiac events $[13,16,18,27,28]$. In these studies, however, the subjects were mostly stable outpatients at study entry, while our study focused on those admitted to the ICU due to acute illness. The significant relation revealed by multivariate analyses in our study between higher BNP levels and the incidence of new cardiac events indicate that BNP level, even when measured in the unstable state as in the ICU setting, could be a useful marker for predicting future cardiac events.

BNP levels are usually elevated in both haemodialysis and peritoneal dialysis patients [29-32]. In subgroup analysis with dialysis-dependent patients, this study demonstrated a similar cutoff level to that of all 136 patients with CKD, and high admission BNP levels were also associated with a high incidence of new cardiac events, which was consistent with previous studies $[16,27,28]$. Although no large-scale trials have been performed on dialysis-dependent patients, these results suggest that BNP levels at admission may still be a useful tool regardless of dialysis state in the ICU.

This study had several limitations. First, this was a retrospective study and the number of patients was limited. Therefore, 
Univariate and multivariate analyses for predictors of new cardiac events

\begin{tabular}{|c|c|c|c|c|}
\hline \multirow[b]{2}{*}{ Variables } & \multicolumn{2}{|c|}{ Univariate analysis } & \multicolumn{2}{|c|}{ Multivariate analysis } \\
\hline & $P$ value & $P$ value & Hazard ratios & $95 \%$ confidence intervals \\
\hline WBC & 0.053 & 0.410 & 1.000 & 1.000 to 1.000 \\
\hline Serum $\mathrm{Cr}$ & 0.044 & 0.046 & 0.855 & 0.734 to 0.997 \\
\hline LVEF (\%) & 0.010 & 0.842 & 0.997 & 0.964 to 1.031 \\
\hline LAD & 0.004 & 0.034 & 1.083 & 1.006 to 1.167 \\
\hline LV mass index & 0.087 & 0.606 & 1.002 & 0.994 to 1.011 \\
\hline C-reactive protein & 0.066 & 0.890 & 0.999 & 0.988 to 1.010 \\
\hline ADHF & 0.038 & 0.780 & 0.816 & 0.197 to 3.385 \\
\hline \multicolumn{5}{|l|}{ Admission BNP } \\
\hline Optimal cutoff level ${ }^{\star}$ & 0.007 & 0.078 & 4.551 & 0.845 to 24.502 \\
\hline BNP (continuous variable) & 0.005 & 0.041 & 1.001 & 1.0002 to 1.0010 \\
\hline BNP quartiles & 0.005 & 0.018 & 2.212 & 1.145 to 4.276 \\
\hline
\end{tabular}

${ }^{*} \mathrm{BNP} \geq 1020.5 \mathrm{pg} / \mathrm{mL}$.

$\mathrm{ADHF}=$ acute decompensated heart failure; $\mathrm{BNP}=$ blood natriuretic peptide; $\mathrm{Cr}=$ creatinine; $\mathrm{LAD}=$ left atrial dimension; $\mathrm{LV}=$ left ventricular;

$\mathrm{LVEF}=$ left ventricular ejection fraction; WBC $=$ white blood cells.

the data may reflect some unintended bias. In particular, of 194 patients with CKD, 58 patients were excluded due to the absence of BNP results. This exclusion might have led to an increased number of patients with ADHF and the elevated BNP levels. Second, the diagnosis of ADHF in this study was made mainly by clinical and radiological findings. However, in clinical practice, patients with ADHF may not have pulmonary oedema in chest radiographs and in some patients with ADHF the radiographic findings are similar to those of ALI/ARDS. Therefore, some misclassification may have occurred in this study. Third, the data for subsequent deaths and cardiac events were based on electronic records. Therefore, even with high adherence of patients with CKD to the institution, outcomes may have been missed. Fourth, we could not investigate the changes in BNP level during ICU stay or BNP levels at discharge, which may reflect the effectiveness of ICU treatment and be associated with patient outcomes [33]. This was mainly due to the nature of this study, which did not have a prognostic design. Fifth, we could not evaluate the degree of patient compliance with prescribed medications, which could have a major impact on clinical outcomes. Despite these limitations, to our knowledge, this is the first study on the clinical utility of BNP levels in patients with CKD in the ICU setting.

\section{Conclusions}

In this study, BNP levels at admission in patients with CKD in the ICU were not associated with in-hospital mortality. However, BNP levels at admission was useful for detecting ADHF and predicting future cardiac events (i.e., CRS type 4) in patients with CKD admitted to the ICU. Therefore, despite var- ious confounding factors, BNP levels at admission may be useful even in critically ill patients with CKD admitted to the ICU. Further prospective studies with larger cohorts are needed to define the precise role of BNP in patients with CKD in the ICU setting.

\section{Key messages}

- $\quad$ BNP levels at admission in the CKD + ADHF group were significantly higher than those in the CKD - ADHF and low-Cr/ADHF groups.

- High BNP level was associated with LV systolic dysfunction and may be helpful for detecting ADHF in patients with CKD in the ICU setting.

- High BNP levels at admission was not associated with in-hospital mortality, but were significantly associated with new cardiac events in patients with CKD admitted to the ICU.

- Despite various confounding factors, BNP levels at admission may be a useful marker for CRS type 4 in ICU patients.

\section{Competing interests}

The authors declare that they have no competing interests.

\section{Authors' contributions}

SP conducted the study, performed data collection and statistical analysis, and drafted the manuscript. GYC reviewed and collected echocardiographic data, and revised the manuscript 
critically. SGK participated in the design of the study and revised the manuscript critically. YIH, HRK, SHJ, DGK and YRS participated in the design and coordination of the study. YAB reviewed chest radiography. KSJ conceived of the study and participated in its design and coordination, and revised the manuscript critically. All authors read and approved the final manuscript.

\section{Acknowledgements}

The authors thank Dr. Young Soo Ju of Hallym University Sacred Hospital for his statistical contribution to this study.

\section{References}

1. Parfrey PS, Foley RN: The clinical epidemiology of cardiac disease in chronic renal failure. J Am Soc Nephrol 1999, 10:1606-1615.

2. US Renal Data System 1992 Annual Report IV: Comorbid conditions and correlations with mortality risk among 3,399 incident hemodialysis patients. Am J Kidney Dis 1992, 20:32-38.

3. Harnett JD, Foley RN, Kent GM, Barre PE, Murray D, Parfrey PS: Congestive heart failure in dialysis patients: prevalence, incidence, prognosis and risk factors. Kidney Int 1995, 47:884-890.

4. Breidthardt T, Mebazaa A, Mueller CE: Predicting progression in nondiabetic kidney disease: the importance of cardiorenal interactions. Kidney Int 2009, 75:253-255.

5. Ronco C, Haapio M, House AA, Anavekar N, Bellomo R: Cardiorenal syndrome. J Am Coll Cardiol 2008, 52:1527-1539.

6. Anand IS, Fisher LD, Chiang YT, Latini R, Masson S, Maggioni AP, Glazer RD, Tognoni G, Cohn JN: Changes in brain natriuretic peptide and norepinephrine over time and mortality and morbidity in the Valsartan Heart Failure Trial (Val-HeFT). Circulation 2003, 107:1278-1283.

7. Maisel AS, Krishnaswamy P, Nowak RM, McCord J, Hollander JE, Duc P, Omland T, Storrow AB, Abraham WT, Wu AH, Clopton P, Steg PG, Westheim A, Knudsen CW, Perez A, Kazanegra R, Herrmann HC, McCullough PA, for the Breathing Not Properly Multinational Study Investigators: Rapid measurement of B-type natriuretic peptide in the emergency diagnosis of heart failure. New Engl J Med 2002, 347:161-167.

8. Mueller C, Scholer A, Laule-Kilian K, Martina B, Schindler C, Buser P, Pfisterer M, Perruchoud AP: Use of B-type natriuretic peptide in the evaluation and management of acute dyspnea. New Engl J Med 2004, 350:647-654.

9. Wieczorek SJ, Wu AH, Christenson R, Krishnaswamy P, Gottlieb S, Rosano T, Hager D, Gardetto N, Chiu A, Bailly KR, Maisel A: A rapid $B$-type natriuretic peptide assay accurately diagnoses left ventricular dysfunction and heart failure: a multicenter evaluation. Am Heart J 2002, 144:834-839.

10. Cataliotti $A$, Malatino LS, Jougasaki $M$, Zoccali $C$, Castellino $P$, Giacone G, Bellanuova I, Tripepi R, Seminara G, Parlongo S, Stancanelli B, Bonanno G, Fatuzzo P, Rapisarda F, Belluardo P, Signorelli SS, Heublein DM, Lainchbury JG, Leskinen HK, Bailey KR, Redfield MM, Burnett JC Jr: Circulating natriuretic peptide concentrations in patients with end-stage renal disease: role of brain natriuretic peptide as a biomarker for ventricular remodeling. Mayo Clin Proc 2001, 76:1111-1119.

11. McCullough PA: Cardiorenal risk: an important clinical intersection. Rev Cardiovasc Med 2002, 3:71-76.

12. Nishikimi T, Futoo $Y$, Tamano K, Takahashi M, Suzuki T, Minami J, Honda T, Útake S, Asakawa H, Kobayashi N, Horinaka S, Ishimitsu $\mathrm{T}$, Matsuoka $\mathrm{H}$ : Plasma brain natriuretic peptide levels in chronic hemodialysis patients: influence of coronary artery disease. Am J Kidney Dis 2001, 37:1201-1208.

13. Austin WJ, Bhalla V, Hernandez-Arce I, Isakson SR, Beede J, Clopton $\mathrm{P}$, Maisel AS, Fitzgerald RL: Correlation and prognostic utility of B-type natriuretic peptide and its amino-terminal fragment in patients with chronic kidney disease. $A m \mathrm{~J}$ Clin Pathol 2006, 126:506-512.

14. McCullough PA, Duc P, Omland T, McCord J, Nowak RM, Hollander JE, Herrmann HC, Steg PG, Westheim A, Knudsen CW, Storrow AB, Abraham WT, Lamba S, Wu AH, Perez A, Clopton P,
Krishnaswamy $\mathrm{P}$, Kazanegra R, Maisel AS, for the Breathing Not Properly Multinational Study Investigators: B-type natriuretic peptide and renal function in the diagnosis of heart failure: an analysis from the Breathing Not Properly Multinational Study. Am J Kidney Dis 2003, 41:571-579.

15. Anwaruddin S, Lloyd-Jones DM, Baggish A, Chen A, Krauser D, Tung R, Chae C, Januzzi JL Jr: Renal function, congestive heart failure, and amino-terminal pro-brain natriuretic peptide measurement: results from the ProBNP Investigation of Dyspnea in the Emergency Department (PRIDE) Study. J Am Coll Cardio/ 2006, 47:91-97.

16. Naganuma T, Sugimura $K$, Wada $S$, Yasumoto $R$, Sugimura $T$, Masuda C, Uchida J, Nakatani T: The prognostic role of brain natriuretic peptides in hemodialysis patients. Am J Nephrol 2002, 22:437-444.

17. Sommerer C, Beimler J, Schwenger V, Heckele N, Katus HA, Giannitsis $E$, Zeier M: Cardiac biomarkers and survival in haemodialysis patients. Eur J Clin Invest 2007, 37:350-356.

18. Takami $Y$, Horio $T$, Iwashima $Y$, Takiuchi $S$, Kamide $K$, Yoshihara $F$, Nakamura S, Nakahama H, Inenaga T, Kangawa K, Kawano $Y$ : Diagnostic and prognostic value of plasma brain natriuretic peptide in non-dialysis-dependent CRF. Am J Kidney Dis 2004, 44:420-428

19. Zeng $C$, Wei $T$, Jin L, Wang L: Value of B-type natriuretic peptide in diagnosing left ventricular dysfunction in dialysisdependent patients. Intern Med J 2006, 36:552-557.

20. Nikolaou NI, Goritsas C, Dede M, Paissios NP, Papavasileiou M, Rombola AT, Ferti A: Brain natriuretic peptide increases in septic patients without severe sepsis or shock. Eur J Intern Med 2007, 18:535-541.

21. Witthaut $R$, Busch $C$, Fraunberger $P$, Walli $A$, Seidel D, Pilz G Stuttmann R, Speichermann N, Verner L, Werdan K: Plasma atrial natriuretic peptide and brain natriuretic peptide are increased in septic shock: impact of interleukin-6 and sepsis-associated left ventricular dysfunction. Intensive Care Med 2003, 29:1696-1702.

22. Abroug F, Ouanes-Besbes L, Nciri N, Sellami N, Addad F, Hamda $\mathrm{KB}$, Amor AB, Najjar MF, Knani J: Association of left-heart dysfunction with severe exacerbation of chronic obstructive pulmonary disease: diagnostic performance of cardiac biomarkers. Am J Respir Crit Care Med 2006, 174:990-996.

23. Karmpaliotis D, Kirtane AJ, Ruisi CP, Polonsky T, Malhotra A, Talmor D, Kosmidou I, Jarolim P, de Lemos JA, Sabatine MS, Gibson $\mathrm{CM}$, Morrow D: Diagnostic and prognostic utility of brain natriuretic Peptide in subjects admitted to the ICU with hypoxic respiratory failure due to noncardiogenic and cardiogenic pulmonary edema. Chest 2007, 131:964-971.

24. Levitt JE, Vinayak AG, Gehlbach BK, Pohlman A, Van Cleve W, Hall JB, Kress JP: Diagnostic utility of B-type natriuretic peptide in critically ill patients with pulmonary edema: a prospective cohort study. Crit Care 2008, 12:R3.

25. Foley RN, Parfrey PS, Sarnak MJ: Clinical epidemiology of cardiovascular disease in chronic renal disease. Am J Kidney Dis 1998, 32:S112-119.

26. Port FK: Mortality and causes of death in patients with endstage renal failure. Am J Kidney Dis 1990, 15:215-217.

27. Goto $T$, Takase $H$, Toriyama $T$, Sugiura T, Kurita $Y$, Tsuru N, Masuda H, Hayashi K, Ueda R, Dohi Y: Increased circulating levels of natriuretic peptides predict future cardiac event in patients with chronic hemodialysis. Nephron 2002, 92:610-615.

28. Zoccali C, Mallamaci F, Benedetto FA, Tripepi G, Parlongo S, Cataliotti A, Cutrupi S, Giacone G, Bellanuova I, Cottini E, Malatino LS, on behalf of the Creed Investigators: Cardiac natriuretic peptides are related to left ventricular mass and function and predict mortality in dialysis patients. J Am Soc Nephrol 2001, 12:1508-1515.

29. Kohse KP, Feifel K, Mayer-Wehrstein R: Differential regulation of brain and atrial natriuretic peptides in hemodialysis patients. Clin Nephrol 1993, 40:83-90.

30. Lang CC, Choy AM, Henderson IS, Coutie WJ, Struthers AD: Effect of haemodialysis on plasma levels of brain natriuretic peptide in patients with chronic renal failure. Clin Sci (Lond) 1992, 82:127-131.

31. Nakatani T, Naganuma T, Masuda C, Uchida J, Sugimura T, Sugimura K: Significance of brain natriuretic peptides in patients on continuous ambulatory peritoneal dialysis. Int $\mathrm{J} \mathrm{Mol} \mathrm{Med}$ $2002,10: 457-461$ 
32. Obineche EN, Pathan JY, Fisher S, Prickett TC, Yandle TG, Frampton CM, Cameron VA, Nicholls MG: Natriuretic peptide and adrenomedullin levels in chronic renal failure and effects of peritoneal dialysis. Kidney Int 2006, 69:152-156.

33. Cheng V, Kazanagra R, Garcia A, Lenert L, Krishnaswamy P, Gardetto N, Clopton P, Maisel A: A rapid bedside test for B-type peptide predicts treatment outcomes in patients admitted for decompensated heart failure: a pilot study. J Am Coll Cardiol 2001, 37:386-391. 